\title{
A novel kind of room temperature self-healing poly(urethane-urea) with robust mechanical strength based on aromatic disulfide
}

\author{
Jin $\mathrm{He}^{1,2} \cdot$ Fangfang Song ${ }^{1} \cdot$ Xiong $\mathrm{Li}^{1} \cdot$ Liyi Chen $^{1} \cdot$ Xingyu Gong ${ }^{1}$ (C) $\cdot$ Weiping $\mathrm{Tu}^{2}$
}

Received: 13 September 2020 / Accepted: 21 January 2021 / Published online: 13 March 2021

(c) The Author(s) 2021

\begin{abstract}
An innovative poly(urethane-urea) elastomer, which exhibited excellent stretchability, thermal stability and autonomous selfhealing abilities, was synthesized from the commercially available poly(propylene glycol) (PPG), isophorone diisocyanate (IPDI), 2,4 / 2,6-toluene diisocyanate (80: 20, w / w) (TDI-80) and bis (2-aminophenyl) disulfide (DSDA). This aromatic disulfide containing poly(urethane-urea) (ss-PUs) achieved both rapid room temperature self-healing abilities and robust mechanical strength (the ultimate tensile strength was up to $4.20 \pm 0.10 \mathrm{MPa}$ and elongation at break was up to $954 \pm 35.6 \%$ ), through facile metathesis of the aromatic disulfides which embedded in hard segments. After the ss-PUs was cut into twohalves and reconnected, the mechanical properties could recover to $\sim 90 \%$ of those of the original samples within $12 \mathrm{~h}$ at room temperature without extra self-healing agents or any change of environmental conditions.
\end{abstract}

Keywords Self-healing $\cdot$ Poly (urethane-urea) $\cdot$ Disulfide bond $\cdot$ Hydrogen bond

\section{Introduction}

Originating from the demanding of more smart and durable materials in daily life, self-healing materials, which are able to autonomously repair damages and fatigues during their usages, are currently attractive among the most popular researches [1-4]. Self-healing materials, especially polymeric self-healing materials, have been widely studied in the past two decades [5]. A variety of methods and material systems related to self-healing have been developed, and there are many materials that can deal with damages or failures [6-8]. Compared with "classic" materials, such as epoxy resins and their composites [9-11], the self-healing materials can be repaired and do not need obvious human intervention when damages or failures occur. These selfhealing materials may remind us of scenes that often

Xingyu Gong

gongxingyu@keshun.com.cn

Weiping Tu

cewptu@scut.edu.cn

1 Department of Research and Development, Keshun Waterproof Technology Co., Ltd, Foshan 528303, China

2 School of Chemistry and Chemical Engineering, South China University of Technology, Guangzhou 510641, China appear in science fictions, like higher regenerability, longer service life, less maintenance (time and cost), more security and better performance. Usually, the self-healing materials can be clarified into two subtypes, namely the extrinsic self-healing materials and the intrinsic selfhealing materials [12]. As for the extrinsic self-healing materials, the self-healing agents are embedded in matrix and released to repair the damage when the damage occurs. White and coworkers firstly reported the extrinsic self-healing materials in 2001 [13]. This system was consisted of the microencapsulated dicyclopentadiene and the epoxy resin matrix containing Grubbs catalyst. When the fractures were formed, the microencapsulated dicyclopentadiene was released and initiated the ring opening metathesis polymerization (ROMP) of the dicyclopentadiene, forming a strong and highly crosslinked network and achieving the self-healing of fractures. This is the basic strategy adopted by many extrinsic self-healing materials. Other kinds of extrinsic self-healing materials are carried out or improved on this basis [14-16]. However, such a self-healing material can only be repaired once at a specific location. Then, Toohey and coworkers developed a 3D microvascular network to repair the repeated or multiple injuries, but the repairing times were still limited [17]. By designing the intrinsic self-healing materials, the defect of limited repairing 
times can be solved. Theoretically, the repairing times of the intrinsic self-healing materials should be infinite. Moreover, other damages, including scratches, punctures, tears, cracks, breakages, or smashes and so on, may happen to these materials. Usually, some external stimuli, such as light [18, 19], electricity [20, 21], magnetic field [22], and thermal stimulus [23], are needed for the selfhealing processes. In some cases, these external trigger stimuli are easy to obtain and control. But in other cases, such as waterproof coatings, it is not convenient to obtain external stimuli because waterproof coatings are generally used in more concealed parts of buildings or constructions. Considering these possibilities, it is very important for some self-healable coatings to possess the self-healing ability at relatively moderate temperature without the need for any additional stimuli.

Disulfide chemistry is special and quite attractive because the disulfides and their corresponding sulfhydryl radicals and thiols are reversible and can exchange whether in solution or in the solid state, which are verified and applied in many researches on self-healing materials [24]. In fact, a variety of explorations on the intrinsic self-healing materials via the thermally reversible $\mathrm{S}-\mathrm{S}$ bond metathesis are attractive, and the aromatic disulfides have been demonstrated to exchange at room temperature [25, 26]. Whereas, their aliphatic counterparts usually require stimuli like light and/or heat for the exchange or metathesis to occur [27, 28]. For example, Odriozola and coworkers prepared a room-temperature selfhealing elastomer based on the metathesis of aromatic disulfides, the elongation at break and the ultimate tensile strength of the elastomer were determined to be $3100 \pm 50 \%$ and $0.81 \pm 0.05 \mathrm{MPa}$, respectively [29]. Hwang and coworkers reported a robust and room temperature self-healable polyurethane IP-SS with a much higher toughness of $26.9 \mathrm{MJ} \bullet \mathrm{m}^{-3}$ and ultimate tensile strength of $6.8 \mathrm{MPa}$, respectively [30]. After the IP-SS film was cut into two-halves and re-connected together, the ultimate tensile strength recovered up to $75 \%$ of that of the original samples as soon as selfhealing at room temperature for $2 \mathrm{~h}$.

Herein, we designed an aromatic disulfide containing poly(urethane-urea) elastomer ss-PUs based on disulfide metathesis exhibiting a rapid room temperature self-healing ability within minutes to hours. The ss-PUs was characterized by incorporating an asymmetric structure IPDI together with TDI-80 into the aromatic disulfide containing hard segments, which preserved the optimal self-healing abilities and enabled robust mechanical strength of the ss-PUs, simultaneously.

\section{Experimental}

\section{Materials}

2,4 / 2,6-toluene diisocyanate (80: 20, w / w) (TDI-80, $80 \%$, technical grade), isophorone diisocyanate (IPDI, $98 \%, \mathrm{AR}$ ), poly (propylene glycol) (PPG, $M_{\mathrm{n}}=2.0 \mathrm{~kg} / \mathrm{mol}$ ), were purchased from Bayer Materials Science (Shanghai, China). 2,2'-ethylenedianiline $\left(\mathrm{C}_{2}\left(\mathrm{PhNH}_{2}\right)_{2}, 98 \%\right.$, AR), bis (2-aminophenyl) disulfide $\left(\mathrm{S}_{2}\left(\mathrm{PhNH}_{2}\right)_{2}, \mathrm{DSDA}, 97 \%, \mathrm{AR}\right)$, dibutyltin dilaurate (DBTDL, 95\%, AR), n-butylamine (98\%, AR), ethyl acetate (EtOAc, 98\%, AR), butyl acetate (BA, 98\%, AR), 1,2,4-trimethylbenzene (98\%, AR), tetrahydrofurane (THF, HPLC grade), methyl red (98\%, AR) and 1-methoxy2-propyl acetate (PMA, 98\%, AR) were purchased from Sigma Aldrich (Shanghai, China). All the reactants or reagents were used as received.

\section{Measurements and characterizations}

Proton nuclear magnetic resonance $\left({ }^{1} \mathrm{H}-\mathrm{NMR}\right)$ spectroscopic experiments were carried out using a Bruker Avance 300 $\mathrm{MHz}$ spectrometer (USA). Gel permeation chromatography (GPC) analyses of prepolymers and the cured elastomers were carried out at $40{ }^{\circ} \mathrm{C}$ using an Agilent 1260 Infinity II GPC instrument equipped with a UV-Vis detector, and a differential refractive index detector, a guard column (PLgel, $10 \mu \mathrm{m}$ ), and three additional columns (PLgel, $10 \mu \mathrm{m}$ ). The flow rate was set as $1 \mathrm{~mL} / \mathrm{min}$ using THF as the eluent. The molecular weights were calculated from standard curve of the polystyrene standards $\left(M_{\mathrm{n}}=0.5 \sim 5000 \mathrm{~kg} / \mathrm{mol}\right.$, polydispersity index $(\mathrm{PDI})=1.02 \sim 1.05)$.

Infra-red (IR) measurements. All of the FT-IR spectra were performed on a Nicolet iS50 FT-IR spectrometer with the compressed $\mathrm{KBr}$ pellets as supports. All spectra were recorded at a resolution of $4 \mathrm{~cm}^{-1}$ with 32 scans ranging from $400 \mathrm{~cm}^{-1}$ to $4000 \mathrm{~cm}^{-1}$ at room temperature. As for the recording of the attenuated total reflectance (ATR) mode of IR, these spectra were also followed with 32 scans per sample. Moreover, the noises of background were corrected with pure $\mathrm{KBr}$ pellets for FI-IR mode and air for ATR mode. The liquid prepolymers were spread evenly onto the $\mathrm{KBr}$ pellets for FT-IR measurements and the cured elastomers were recorded directly with ATR mode.

Tensile tests were conducted with samples (dumbbellshaped, $1.3 \sim 2.0 \mathrm{~mm}$ in thickness) at $25^{\circ} \mathrm{C}$ and the strain rate was set as $500 \mathrm{~mm} / \mathrm{min}$ according to ASTM D412-16 using a WANCE ETM 503B universal tester. These samples were completely cut into two-halves and then manually re-connected before being subjected to tensile tests again so as to evaluate 
the self-healing ability of these samples at $25^{\circ} \mathrm{C}$ or $60^{\circ} \mathrm{C}$ for a period of time. The quantification of self-healing efficiency was calculated by dividing the ultimate tensile strength or elongation at break of the healed samples to that of the original samples, just as the following equation Eq. (1) and Eq. (2) presented [31, 32]:

$R_{\sigma}(\%)=\sigma_{\text {healing }} / \sigma_{\text {original }} \times 100$

$R_{\varepsilon}(\%)=\varepsilon_{\text {healing }} / \varepsilon_{\text {original }} \times 100$

where, $\sigma_{\text {original }}, \sigma_{\text {healing }}$ and $\varepsilon_{\text {original }}, \varepsilon_{\text {healing }}$ were the ultimate tensile strength and elongation at break of the original samples and the healed samples, respectively.

Thermal properties of the polymers were performed for the determination of the glass transition temperature $\left(T_{\mathrm{g}}\right)$ by differential scanning calorimetry (DSC) and thermal degradation temperature $\left(T_{\mathrm{d}}\right)$ by thermal gravimetric analysis (TGA), respectively. The DSC measurements were conducted on a Mettler Toledo Instruments DSC 3 + differential scanning calorimeter at a rate of $10{ }^{\circ} \mathrm{C} / \mathrm{min}$ from $-80{ }^{\circ} \mathrm{C}$ to $200{ }^{\circ} \mathrm{C}$ under $\mathrm{N}_{2}$ flow with heating and cooling cycles (cycles: cooling to $-80{ }^{\circ} \mathrm{C}$, heating up to $200{ }^{\circ} \mathrm{C}$ (as the 1 st run), then cooling to $-80{ }^{\circ} \mathrm{C}$, and heating up to $200{ }^{\circ} \mathrm{C}$ (as the 2 nd run), and cooling to $-80{ }^{\circ} \mathrm{C}$ ). The values of $T_{\mathrm{g}}$ were determined from the 2 nd cycle. The TGA measurements were conducted on a Mettler Toledo TGA-2 Instruments with a heating rate of $10{ }^{\circ} \mathrm{C} / \mathrm{min}$ under $\mathrm{N}_{2}$ atmosphere and the onset $T_{\mathrm{d}}$ values of these poly(urethane-urea) elastomers were obtained. For example, $5 \sim 10 \mathrm{mg}$ polymer samples were weighed and placed into a pan made of platinum and then elevated temperature from $35^{\circ} \mathrm{C}$ to $800{ }^{\circ} \mathrm{C}$. To remove the residual solvents, polymer samples were dried under vacuum at $35{ }^{\circ} \mathrm{C}$ overnight before TGA measurements.

Optical microscopy. Self-healing behaviors of ss-PUs and cc-PUs were observed by an optical microscope (Leica DMV6, Germany). Fresh scratches were made on the surfaces of ss-PUs and cc-PUs with a sharp blade and their self-healing processes at room temperature were monitored.

Rheological measurements. Viscoelastic properties including the storage modulus $\left(\mathrm{G}^{\prime}\right)$ and the loss modulus $\left(\mathrm{G}^{\prime \prime}\right)$ of ss-PUs and cc-PUs were measured on an Anton Paar Rheocompass ${ }^{\mathrm{TM}}$ MCR 302 Instrument (Anton Paar GmbH, Austria). The amplitude oscillatory shear mode was adopted with a $25 \mathrm{~mm}$ parallel plate in diameter. An axial force $\sim 1 \mathrm{~N}$ was obtained at room temperature by setting up the gap as $1 \mathrm{~mm}$. In addition, self-healing of viscoelastic properties of ss-PUs and cc-PUs were measured by changing the amplitude oscillatory from 5\% shear strain for $1500 \mathrm{~s}$ to $100 \%$ shear strain for $500 \mathrm{~s}$. These cycles were repeated three times. The region of linear response was determined by strain sweep experiments performed at a frequency of $1 \mathrm{~Hz}$. Accordingly, the frequency sweep experiments ranging from $0.1 \mathrm{~Hz}$ to $100 \mathrm{~Hz}$ with $0.1 \%$ shear strain were performed at different temperatures and temperature sweep was varied from $20^{\circ} \mathrm{C}$ to $130{ }^{\circ} \mathrm{C}$ at a frequency of $1 \mathrm{~Hz}$ with $0.1 \%$ shear strain.

Atomic force microscopy (AFM) of ss-PUs and cc-PUs were captured at $25^{\circ} \mathrm{C}$ by applying a resonance of $75 \mathrm{kHz}$, collecting the morphology and phase images simultaneously. A nano-scope $\mathrm{V}$ scanning probe microscope (Dimension Icon Bruker Digital Instruments) and a cantilever (RFESP75 , Bruker, USA) with a length of $225 \mu \mathrm{m}$ and a spring constant of $3 \mathrm{~N} / \mathrm{m}$ were utilized.

Dynamic mechanical analysis (DMA) of slice samples $(15 \mathrm{~mm} \times 5 \mathrm{~mm} \times 1.5 \mathrm{~mm})$ was conducted in the tensile mode using a Mettler Toledo DMA1 Instruments. The gauge length of the samples between the tensile grips was set as $10 \mathrm{~mm}$ for all tests. Stress-relaxation behaviors were performed with a tensile strain of $5 \%$ at $25{ }^{\circ} \mathrm{C}$ and $60{ }^{\circ} \mathrm{C}$, respectively.

\section{Synthesis of the bis-isocyanate-terminated prepolymer 1}

PPG (250 g, $125 \mathrm{mmol})$ was fed into a $1000 \mathrm{~mL}$, threenecked, round-bottomed flask which equipped with a mechanical stirrer and a vacuum inlet. The mixture was heated up to $105^{\circ} \mathrm{C}$ and degassed under vacuum for $3 \mathrm{~h}$. After cooling to $60^{\circ} \mathrm{C}$, then DBTDL $(0.3 \mathrm{~g}, 0.475 \mathrm{mmol})$ and IPDI (65.6 g, $250 \mathrm{mmol}$ ) were added under $\mathrm{N}_{2}$ atmosphere and the reaction was further proceeded for $3 \mathrm{~h}$ at $80^{\circ} \mathrm{C}$. The reaction was monitored by the acid-base titration and FT-IR spectroscopy. The prepolymer $\mathbf{1}$ was obtained as a colorless liquid and stored under $\mathrm{N}_{2}$ atmosphere. Yield: $301 \mathrm{~g}, 98 \%$.

\section{Synthesis of disulfide containing amino-terminated prepolymer $2 \mathbf{a}$}

A mixture of 1,2,4-trimethylbenzene (20 g) and DSDA $(51.7 \mathrm{~g}, 208.6 \mathrm{mmol})$ was fed into a $1000 \mathrm{~mL}$, threenecked, round-bottomed flask which equipped with a mechanical stirrer and a vacuum inlet. The mixture was heated up to $105^{\circ} \mathrm{C}$ and degassed under vacuum for $10 \mathrm{~min}$. After cooling to $85^{\circ} \mathrm{C}$, prepolymer 1 (295 g, $120 \mathrm{mmol}$ ) was added under $\mathrm{N}_{2}$ atmosphere and the mixture was further stirred for $6 \mathrm{~h}$ at $85^{\circ} \mathrm{C}$. The reaction was monitored by FT-IR spectroscopy, then $50 \mathrm{~g}$ PMA and BA mixture (1: 1, w/w) was fed into the reaction and the viscosity of the mixture was $\sim 20,000 \mathrm{mPa} \bullet \mathrm{s}$. The resulting disulfide containing amino-terminated prepolymer $\mathbf{2 a}$ was obtained as a yellowish liquid. 

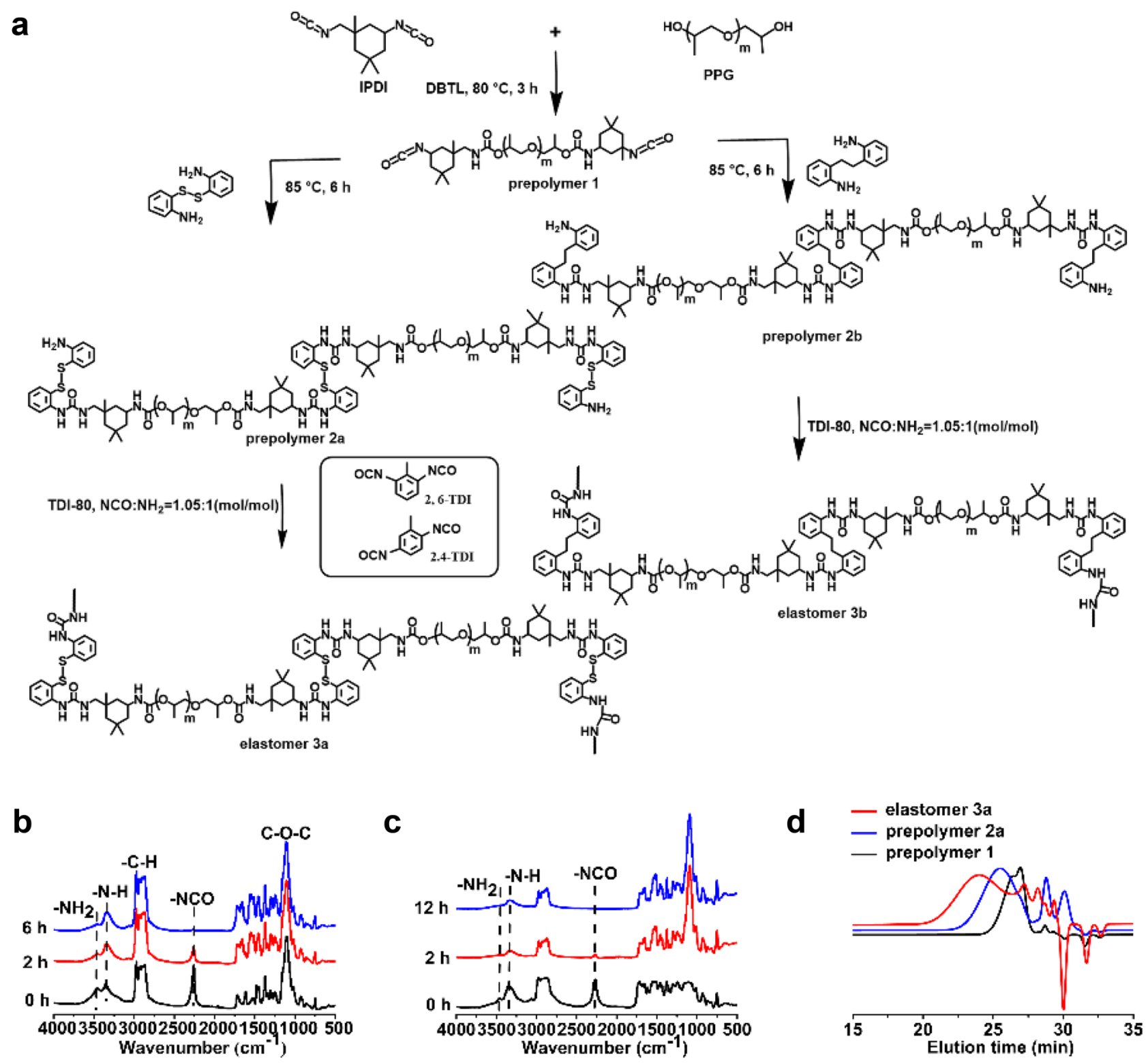

Fig. 1 a Synthetic routes of aromatic disulfide containing poly(urethane-urea) elastomer 3a (ss-PUs) and the reference poly(urethane-urea) elastomer 3b (cc-PUs) as control; b FT-IR spectra of the reaction between prepolymer 1 and DSDA at $85^{\circ} \mathrm{C}$; $\mathbf{c}$ FT-IR

\section{Synthesis of the reference amino-terminated prepolymer $\mathbf{2 b}$}

A mixture of 1,2,4-trimethylbenzene $(20 \mathrm{~g})$ and 2,2'-ethylenedianiline $(44.3 \mathrm{~g}, 208.6 \mathrm{mmol})$ were fed into a $1000 \mathrm{~mL}$, three-necked, round-bottomed flask which equipped with a mechanical stirrer and a vacuum inlet. The mixture was heated up to $105^{\circ} \mathrm{C}$ and degassed under vacuum for $10 \mathrm{~min}$. After cooling to $85^{\circ} \mathrm{C}$, prepolymer $1(295 \mathrm{~g}, 120 \mathrm{mmol})$ was added under $\mathrm{N}_{2}$ atmosphere and the mixture was further stirred for $6 \mathrm{~h}$ at $85^{\circ} \mathrm{C}$. The reaction was monitored by FT-IR spectra recorded for the synthesis of elastomer 3a at different curing time; $\mathbf{d}$ GPC analyses of the prepolymers and the poly(urethane-urea) ss-PUs; the flow rate was $1.0 \mathrm{~mL} / \mathrm{min}$ using THF as the eluent.

spectroscopy and then $50 \mathrm{~g}$ of PMA and BA mixture (1: $1, \mathrm{w}$ $/ \mathrm{w}$ ) was fed into the reaction and the viscosity of the mixture was $\sim 22,000 \mathrm{mPa} \bullet$ s. The resulting disulfide containing aminoterminated prepolymer $\mathbf{2} \mathbf{b}$ was obtained as a colorless liquid.

\section{Preparation of self-healing poly(urethane-urea) elastomer 3a (ss-PUs)}

To a solution of prepolymer $\mathbf{2 a}(50 \mathrm{~g}, 20.6 \mathrm{mmol})$, TDI-80 $(3.76 \mathrm{~g}, 21.6 \mathrm{mmol})$ was added under mechanical stirring at $25^{\circ} \mathrm{C}$. The mixture was placed on to an open mold after 
Fig. $2{ }^{1} \mathrm{H}-\mathrm{NMR}$ spectra of a elastomer 3a, b prepolymer $\mathbf{2 a}$ and $\mathbf{c}$ prepolymer $\mathbf{1}$, respectively

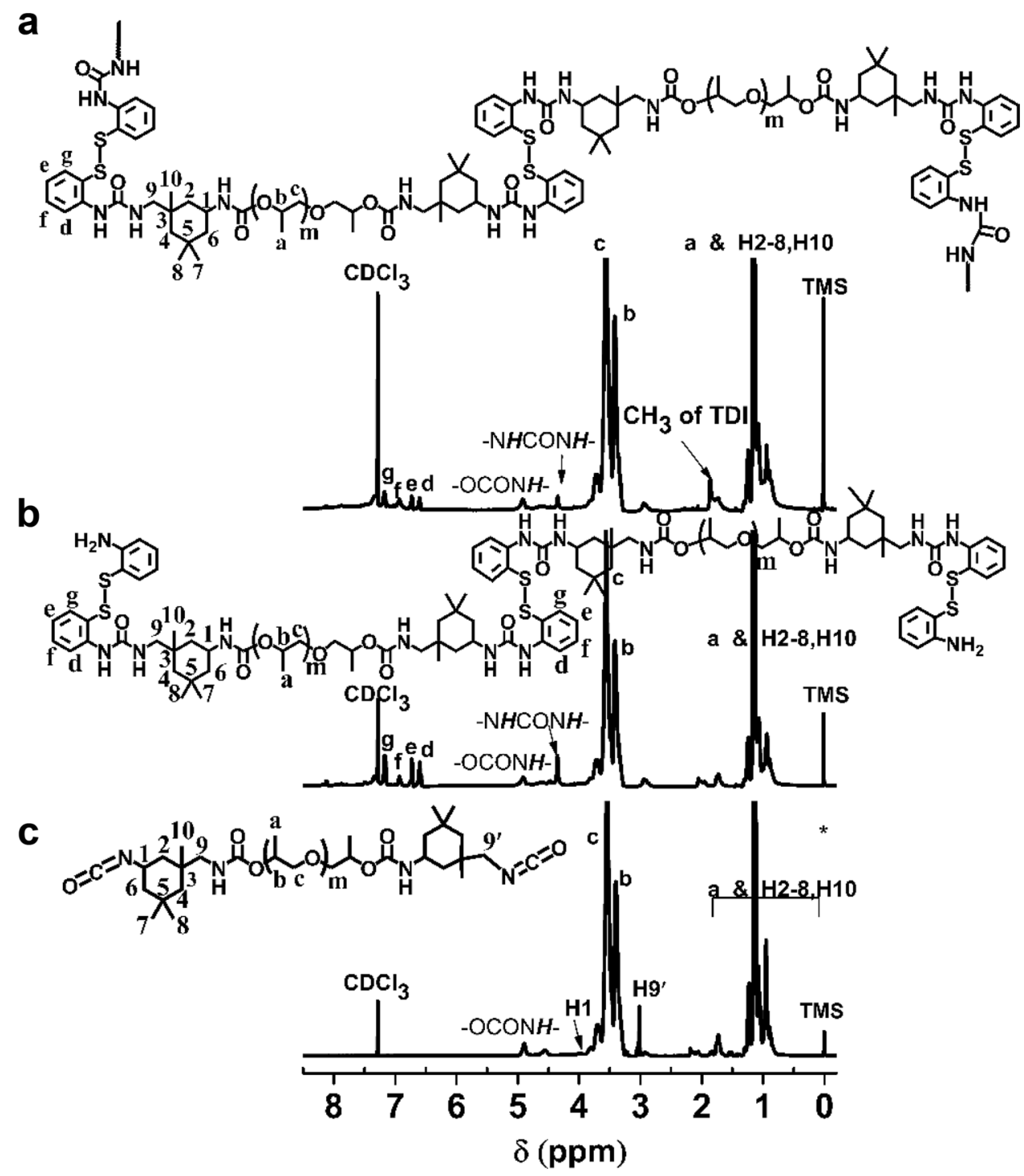

degassing under vacuum for $5 \mathrm{~min}$. The curing process was conducted at $25^{\circ} \mathrm{C}$ and monitored by FT-IR spectroscopy. The aromatic disulfide containing poly(urethane-urea) elastomer 3a was obtained as a transparent yellowish elastomeric film.

\section{Preparation of the reference poly(urethane-urea) elastomer $\mathbf{3 b}$ (cc-PUs)}

To a solution of prepolymer $\mathbf{2 b}$ (49.2 g, $20.6 \mathrm{mmol})$, TDI-80 (3.76 g, $21.6 \mathrm{mmol}$ ) was added under mechanical stirring at $25^{\circ} \mathrm{C}$. The mixture was placed on to an open mold after degassing under vacuum for $5 \mathrm{~min}$. The curing process was conducted at $25^{\circ} \mathrm{C}$ and was monitored by FT-IR spectroscopy. The reference poly(urethane-urea) elastomer 3b was obtained as a transparent colorless elastomeric film.

\section{Results and discussion}

\section{Synthesis and characterization of the aromatic disulfide containing poly(urethane-urea)}

In this work, we presented a novel strategy for preserving the mechanical properties and self-healing ability of poly(urethane-urea) materials. The key was, which build a phase-locked poly(urethane-urea) elastomer with dynamic aromatic disulfide bonds, termed ss-PUs. The ss-PUs provided a self-healable dual dynamic network consisting of both hydrogen bonds and reversible aromatic disulfide bonds. As presented in Fig. 1a, poly(urethaneurea) elastomer 3a (ss-PUs) was readily synthesized and prepared from commercially available PPG, IPDI, DSDA and TDI-80, using DBTDL as the catalyst. The ${ }^{1} \mathrm{H}-\mathrm{NMR}$ spectrum of prepolymer 1 was shown in Fig. $2 \mathrm{c}$. 
Fig. 3 AFM images of ss-PUs a height $\mathbf{c}$ phase and cc-PUs b height $\mathbf{d}$ phase. The scale bars were both $1 \mu \mathrm{m}$
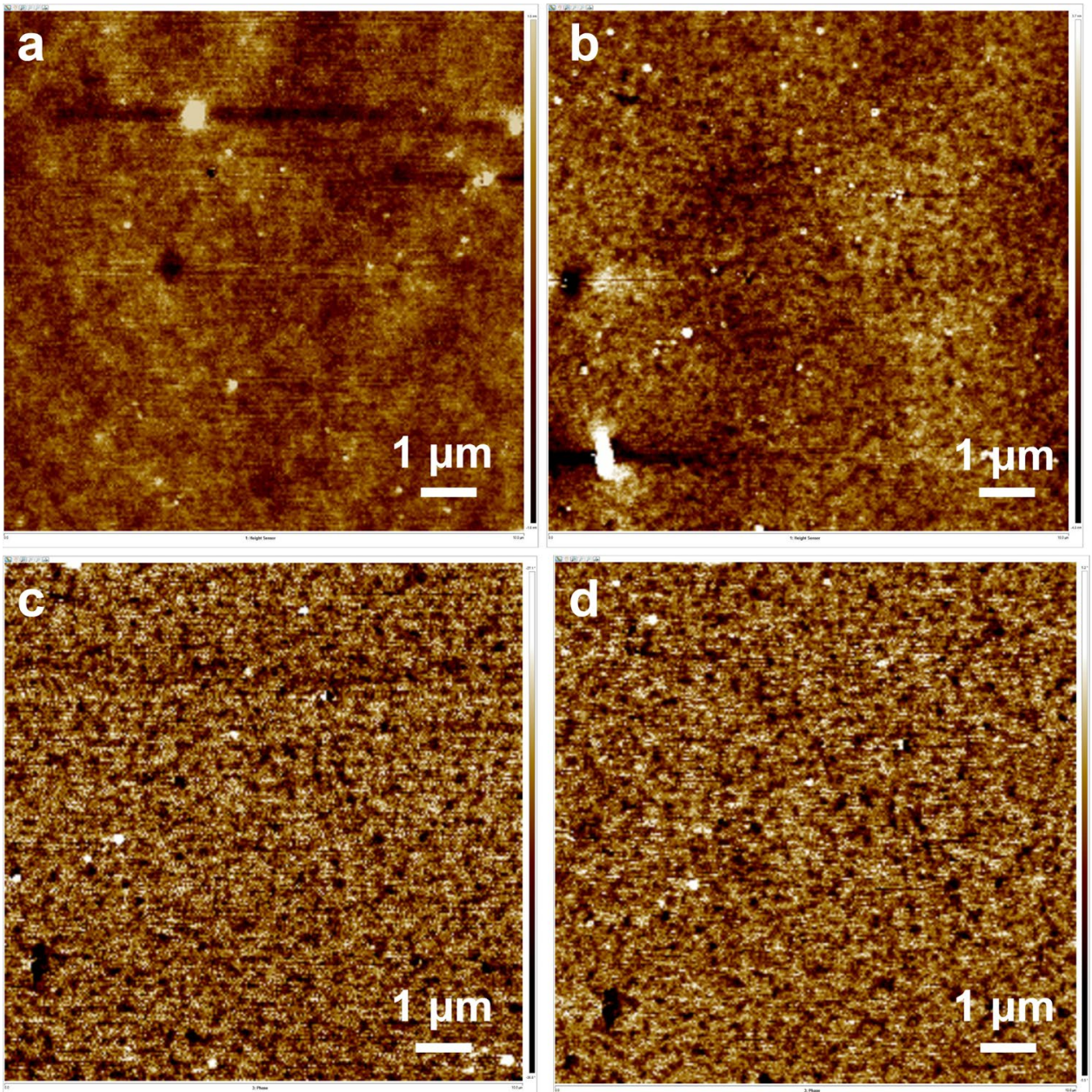

${ }^{1} \mathrm{H}-\mathrm{NMR}\left(\mathrm{CDCl}_{3}, 300 \mathrm{MHz}\right) \delta(\mathrm{ppm}): 4.89$ (s), 4.55 (s), $3.98(\mathrm{~m}), 3.21 \sim 3.73(\mathrm{~m}), 3.02(\mathrm{~d}), 0.75 \sim 1.34(\mathrm{~m})$. The NCO content of prepolymer 1 was determined to $3.47 \%$ by ${ }^{1} \mathrm{H}-\mathrm{NMR}$ and the molar ratio of the primary and secondary isocyanate end groups in prepolymer 1 was determined to be $\sim 20$ : 80 by calculation of the integral ratios of each unit. In addition, the determined $\mathrm{NCO}$ content $(3.48 \pm 0.04 \%)$ by titration was also in accordance with the theoretical estimation $(3.44 \%)$. As for the synthesis of prepolymer 2a, it was observed

Table 1 GPC analyses of pre-polymers and elastomers

\begin{tabular}{lccc}
\hline Polymer name & $M_{\mathrm{n}}{ }^{\mathrm{a}}(\mathrm{kg} / \mathrm{mol})$ & $M_{\mathrm{w}}{ }^{\mathrm{b}}(\mathrm{kg} / \mathrm{mol})$ & $\mathrm{PDI}^{\mathrm{c}}$ \\
\hline Prepolymer 1 & 2.9 & 3.4 & 1.16 \\
Prepolymer 2a & 9.3 & 11.7 & 1.25 \\
Prepolymer 2b & 9.7 & 11.6 & 1.20 \\
elastomer 3a (ss-PUs) & 75.6 & 172.1 & 2.28 \\
elastomer 3b (cc-PUs) & 31.7 & 86.1 & 2.72 \\
\hline
\end{tabular}

${ }^{a}$ Number-average molecular weight.

${ }^{\mathrm{b}}$ Weight-average molecular weight.

${ }^{\mathrm{c}} \mathrm{PDI}=M_{\mathrm{w}} / M_{\mathrm{n}}$. during the reaction that the peak corresponding to - $\mathrm{NCO}$ at $2262 \mathrm{~cm}^{-1}$ and the absorption peak corresponding to $-\mathrm{NH}_{2}$ at $3462 \mathrm{~cm}^{-1}$ decreased, while the absorption peak corresponding to -NH- at $3354 \mathrm{~cm}^{-1}$ increased slightly (Fig. 1b). As illustrated in Fig. 1c, the structure of ss-PUs was also characterized by FT-IR. In addition, ${ }^{1} \mathrm{H}-\mathrm{NMR}$ spectrum of elastomer 3a is shown in Fig. 2a, the peaks of aromatic disulfide unit appeared at $7.55 \sim 6.53 \mathrm{ppm}$, the peaks of PPG protons appeared at $3.73 \sim 3.21 \mathrm{ppm}$ $\left[-\mathrm{CH}\left(\mathrm{CH}_{3}\right) \mathrm{CH}_{2} \mathrm{O}-\right]$ and $1.15 \mathrm{ppm}\left[-\mathrm{CH}\left(\mathrm{CH}_{3}\right) \mathrm{CH}_{2} \mathrm{O}-\right.$ ], the peaks of urethane and urea groups appeared at $4.89 \mathrm{ppm}(-\mathrm{OCON} \boldsymbol{H}-)$ and $4.33 \mathrm{ppm}(-\mathrm{NHCONH}-)$, the peaks of $-\mathrm{CH}_{3}$ belonging to TDI- 80 appeared at $1.77 \sim 1.85 \mathrm{ppm}$ and the peaks of alkyl unit belonging to IPDI appeared at $1.34 \sim 0.75 \mathrm{ppm}$. Integral ratios of each units were well-matched with the feed molar ratio. Accordingly, the GPC analyses of the pre-polymers and the self-healing poly(urethane-urea) elastomers 3a were furtherly determined and the values were determined to be $M_{\mathrm{n}}=2.9 \mathrm{~kg} / \mathrm{mol}$ and PDI $=1.16$ for prepolymer $\mathbf{1}, M_{\mathrm{n}}=9.3 \mathrm{~kg} / \mathrm{mol}$ and PDI $=1.25$ for prepolymer $\mathbf{2 a}$, and $M_{\mathrm{n}}=75.6 \mathrm{~kg} / \mathrm{mol}$ and PDI $=2.28$ for elastomer $\mathbf{3 a}$, respectively (Fig. 1d and Table 1). 

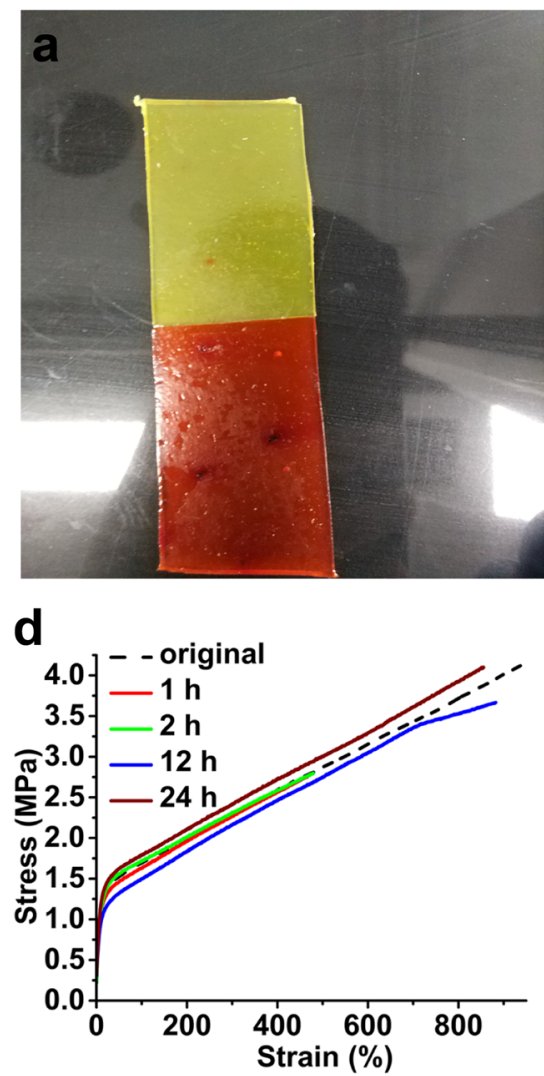
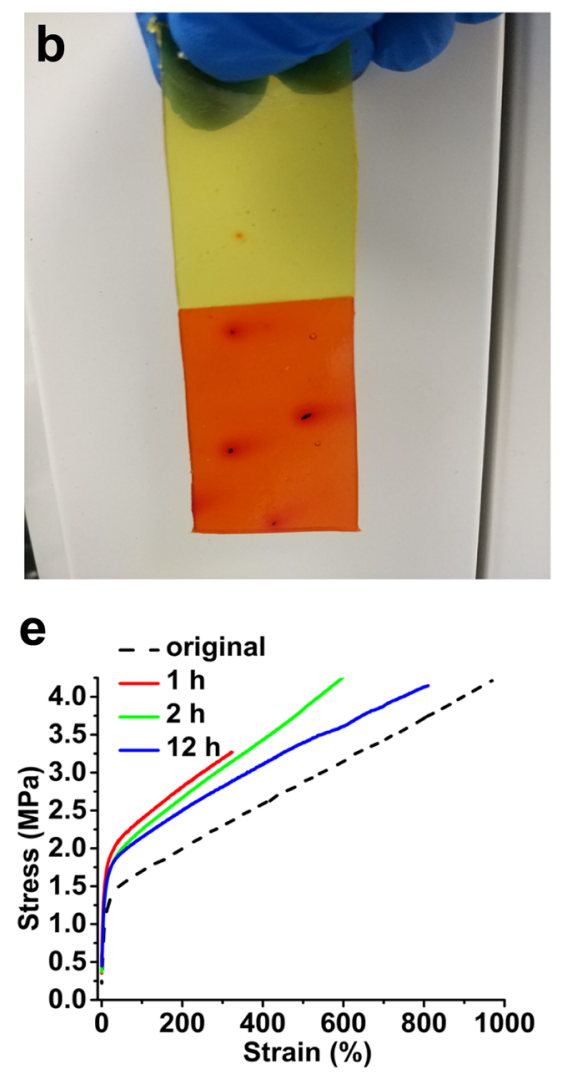
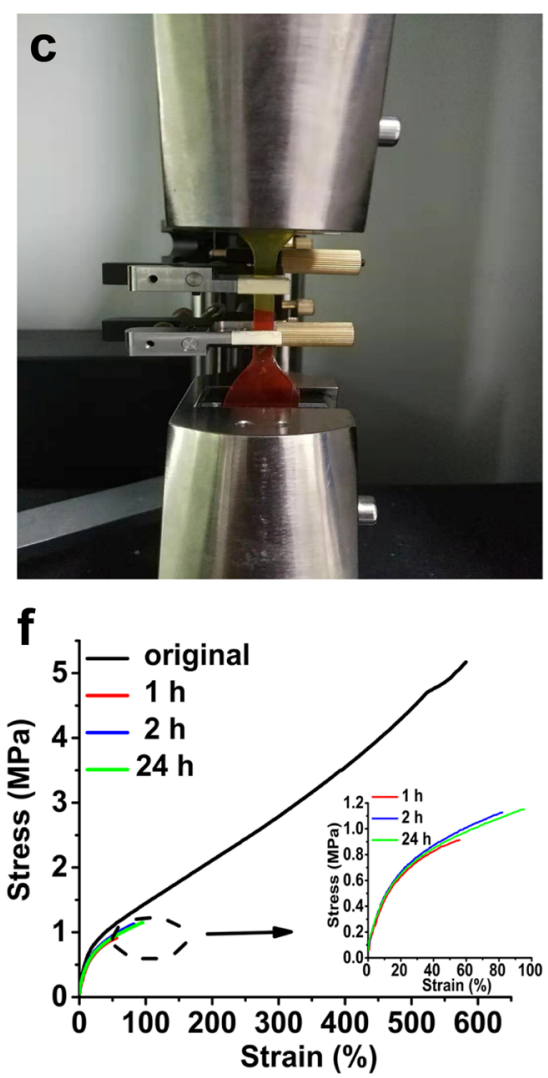

Fig. 4 Photographic sequence of a a pristine sample of ss-PUs (yellow) and methyl red stained ss-PUs (red), which were cut into twohalves and manually re-connected; $\mathbf{b}$ the two-halves were then allowed to withstand their own weights by simply re-connected for $10 \mathrm{~min}$ at $25^{\circ} \mathrm{C}$; $\mathbf{c}$ after $2 \mathrm{~h}$ the healed material could be stretched and the final ultimate tensile strength of the material after healing for

\section{Self-healing behaviors of poly(urethane-urea) elastomers}

IPDI was selected together with TDI- 80 as the hard segments, because its steric cyclohexyl ring inhibited the crystallization of hard segments and increased the chain mobility which was beneficial for the self-healing processes. Moreover, the resulting bulky structures of IPDI derived urethane and urea were more dynamic due to their steric influence, which further facilitated the reconstruction and metathesis of the aromatic disulfide bonds. As for the soft segments, PPG was a good option because its flexible chain would facilitate the motion of the polymer chains. The microphase separation structures of the self-healing ss-PUs and the reference cc-PUs were furtherly characterized and verified by AFM measurements. The AFM results showed the aggregation of both the hard segments and the soft segments (Fig. 3c and d). The aromatic disulfide bonds embedded in the hard segments functioned as dynamic conjugations in the ss-PUs which mainly attributed to their
$24 \mathrm{~h}$ was detected by tensile test; $\mathbf{d}$ stress-strain curves obtained for self-healing elastomer ss-PUs after healing at $25^{\circ} \mathrm{C}$; e stress-strain curves obtained for self-healing elastomer ss-PUs after healing at $60{ }^{\circ} \mathrm{C}$; $\mathbf{f}$ stress-strain curves of the reference cc-PUs after self-healing at $25^{\circ} \mathrm{C}$

self-healing abilities. The soft segments acted as the matrix of the ss-PUs and enabled their high stretch-abilities.

The self-healing of ss-PUs was mainly dependent on the interaction of hydrogen bonds and the aromatic disulfide metathesis between different polymer chains. To visualize the excellent room temperature self-healing behaviors of the ss-PUs samples, these ss-PUs samples with a thickness of $\sim 1.5 \mathrm{~mm}$ were colored red and yellow by staining and cut into two-halves subsequently. Then, the full-cut pieces were re-connected and healing for a period of time at $25^{\circ} \mathrm{C}$ (Fig. 4a). The self-healed samples of ss-PUs were able to weigh themselves without tearing off after self-healing for $10 \mathrm{~min}$ (Fig. 4b). The samples were able to undergo tensile test (Fig. 4c) and the ultimate tensile strength was $4.18 \pm 0.07 \mathrm{MPa}$ after a self-healing process at $25^{\circ} \mathrm{C}$ for $24 \mathrm{~h}$. In order to investigate and quantify the self-healing properties of the ss-PUs after full-cut breakage, the original ss-PUs samples were cut into two-halves and then re-connected for a period of time at $25^{\circ} \mathrm{C}$ and $60{ }^{\circ} \mathrm{C}$, respectively. The results showed that the ss-PUs possessed excellent capability 
Table 2 Mechanical properties and self-healing efficiencies from tensile tests for ss-PUs and the reference cc-PUs as control, means, and standard deviations from five specimens

\begin{tabular}{|c|c|c|c|c|c|c|}
\hline Temperature & $\begin{array}{l}\text { Time } \\
\text { (h) }\end{array}$ & $\begin{array}{l}\text { Young's modulus } \\
(\mathrm{MPa})\end{array}$ & $\begin{array}{l}\text { Ultimate ten- } \\
\text { sile strength } \\
(\mathrm{MPa})\end{array}$ & $\begin{array}{l}\text { Elongation } \\
\text { at break (\%) }\end{array}$ & $\begin{array}{l}R_{\sigma} \\
(\%)\end{array}$ & $\begin{array}{l}R_{\varepsilon} \\
(\%)\end{array}$ \\
\hline \multirow{6}{*}{$\begin{array}{l}25^{\circ} \mathrm{C} \\
\text { (ss-PUs) }\end{array}$} & original & $16.6 \pm 0.6$ & $4.20 \pm 0.10$ & $954 \pm 35.6$ & & \\
\hline & 1 & $17.6 \pm 0.4$ & $2.72 \pm 0.09$ & $459 \pm 19.4$ & $64.8 \pm 2.1$ & $48.1 \pm 2.0$ \\
\hline & 2 & $16.2 \pm 0.8$ & $2.83 \pm 0.08$ & $475 \pm 7.4$ & $67.4 \pm 1.9$ & $49.8 \pm 0.8$ \\
\hline & 12 & $15.5 \pm 0.7$ & $3.78 \pm 0.16$ & $864 \pm 45.8$ & $90.0 \pm 3.8$ & $90.6 \pm 4.8$ \\
\hline & 24 & $16.9 \pm 2.0$ & $4.18 \pm 0.07$ & $903 \pm 78.0$ & $99.5 \pm 1.7$ & $94.7 \pm 8.2$ \\
\hline & reference & $10.0 \pm 0.2$ & $5.06 \pm 0.14$ & $587 \pm 17.1$ & & \\
\hline \multirow{3}{*}{$\begin{array}{l}25^{\circ} \mathrm{C} \\
\text { (cc-PUs) }\end{array}$} & 1 & $9.1 \pm 0.6$ & $0.90 \pm 0.06$ & $52 \pm 2.7$ & $17.8 \pm 0.12$ & $8.9 \pm 0.5$ \\
\hline & 2 & $10.8 \pm 1.7$ & $1.11 \pm 0.07$ & $80 \pm 3.4$ & $21.9 \pm 0.14$ & $13.6 \pm 0.6$ \\
\hline & 24 & $8.1 \pm 0.2$ & $1.14 \pm 0.11$ & $94 \pm 1.9$ & $22.5 \pm 0.22$ & $16.0 \pm 0.3$ \\
\hline \multirow{6}{*}{$\begin{array}{l}60^{\circ} \mathrm{C} \\
\text { (ss-PUs) }\end{array}$} & 1 (uncut) & $18.6 \pm 1.9$ & $4.76 \pm 0.25$ & $803 \pm 68.1$ & & \\
\hline & 1 & $25.3 \pm 2.6$ & $3.11 \pm 0.27$ & $322 \pm 37.8$ & $65.3 \pm 5.7$ & $40.1 \pm 4.7$ \\
\hline & 2 (uncut) & $20.8 \pm 1.3$ & $4.46 \pm 0.13$ & $845 \pm 71.2$ & & \\
\hline & 2 & $23.3 \pm 1.3$ & $4.54 \pm 0.15$ & $622 \pm 31.4$ & $101.8 \pm 3.4$ & $73.6 \pm 3.7$ \\
\hline & 12 (uncut) & $22.2 \pm 1.5$ & $4.40 \pm 0.38$ & $844 \pm 99.7$ & & \\
\hline & 12 & $23.9 \pm 1.5$ & $4.37 \pm 0.16$ & $807 \pm 17.9$ & $99.3 \pm 3.6$ & $95.6 \pm 2.1$ \\
\hline
\end{tabular}

*Young's modulus was determined from the initial slope of the stress-strain curves. of self-healing without any catalyst. The self-healing efficiencies of aromatic disulfide containing ss-PUs were determined to be $R_{\sigma}=99.5 \pm 1.7 \% \& R_{\varepsilon}=94.7 \pm 8.2 \%$ for $24 \mathrm{~h}$ at $25^{\circ} \mathrm{C}$, and $R_{\sigma}=101.8 \pm 3.4 \% \& R_{\varepsilon}=73.6 \pm 3.7 \%$ for $2 \mathrm{~h}$ at $60^{\circ} \mathrm{C}$, respectively (Fig. $4 \mathrm{~d}$, e and Table 2). While, as shown in Fig. $4 \mathrm{f}$ and Table 2, the self-healing efficiency of the reference cc-PUs was no more than $30 \%$ at $25{ }^{\circ} \mathrm{C}$ for $24 \mathrm{~h}$. Moreover, the self-healing processes of scratches (ca. 30 70 $\mu \mathrm{m}$ wide, $\sim 1 \mathrm{~mm}$ long) on ss-PUs were further observed by an optical microscopy (Leica, Germany). As shown in Fig. 5, the ss-PUs achieved full scratch recovery within $8 \mathrm{~h}$ at $25{ }^{\circ} \mathrm{C}$, while the cc-PUs showed no scratch recovery behavior within $24 \mathrm{~h}$ at $25^{\circ} \mathrm{C}$ (Fig. 5f).

\section{Rheometric analysis of poly(urethane-urea) elastomers}

As mentioned previously, the polymer chains containing the dynamic aromatic disulfide bonds and the hydrogen bonds, were predominantly embedded in the hard segments surrounded by the soft PPG segments. The polymer-chain rearrangement and the stress relaxation of ss-PUs could be activated by heating or elevating the temperature. After the glassy microphase being activated by heating, the metathesis and rearrangement of dynamic aromatic disulfides were enabled. The viscoelastic properties of ss-PUs were measured by rheological experiments in

b
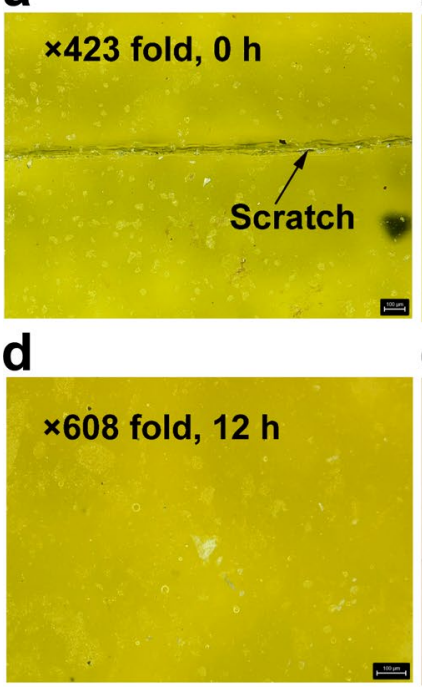

C

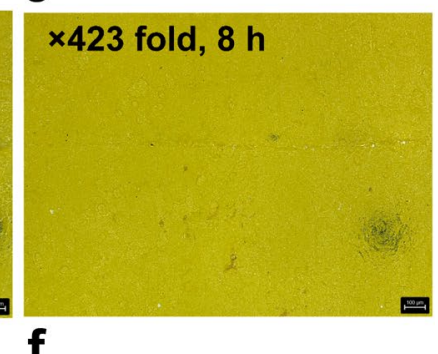

e

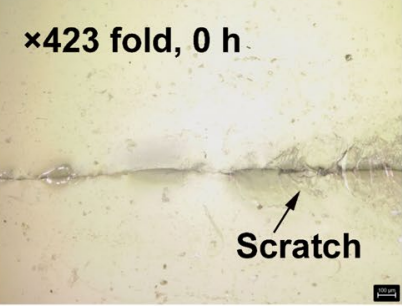

$\times 423$ fold, $24 \mathrm{~h}$ 

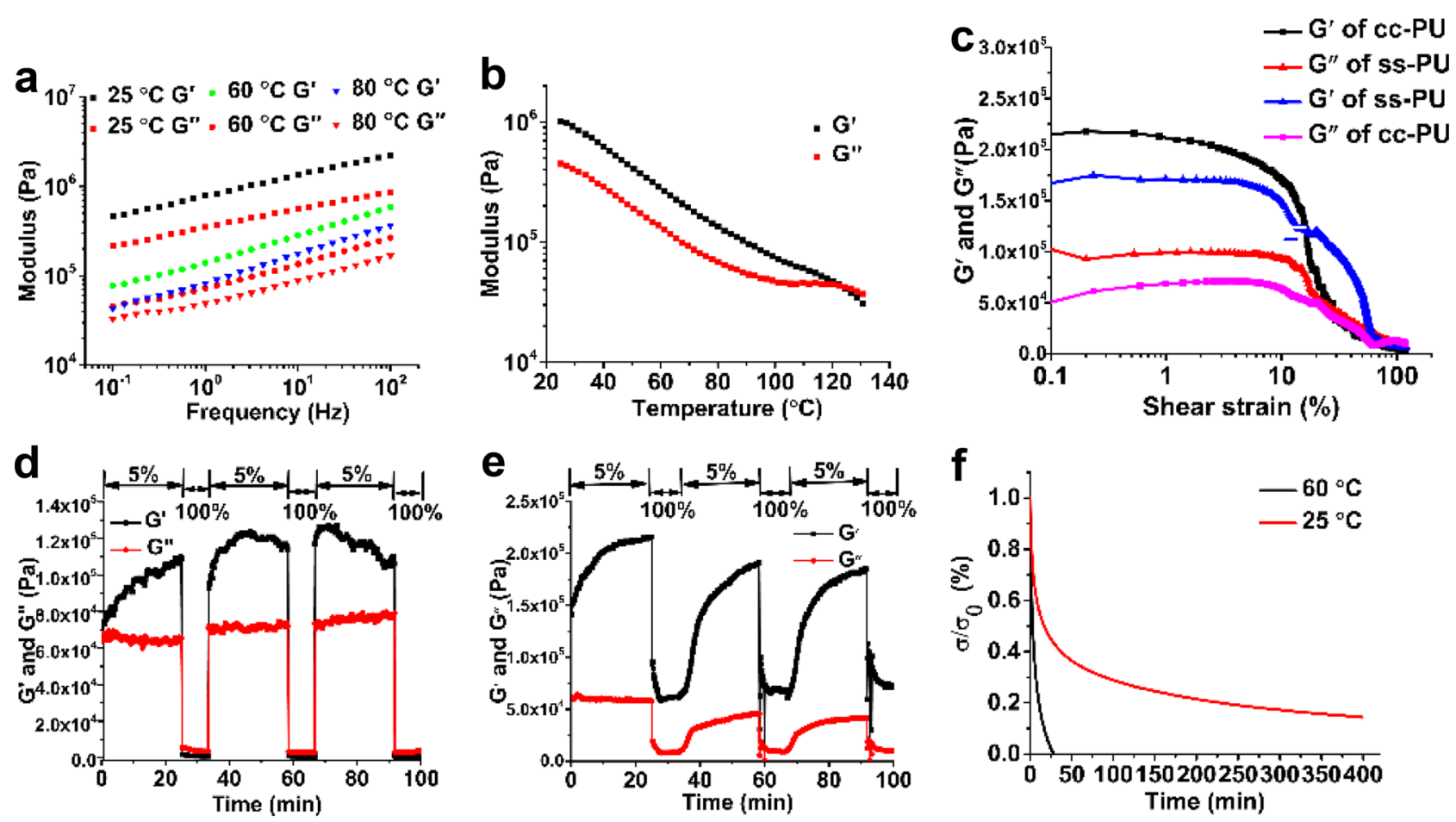

Fig. 6 Variation of $\mathrm{G}^{\prime}$ and $\mathrm{G}^{\prime \prime}$ modulus with temperature and frequency for ss-PUs: a frequency sweep at different temperatures; b temperature sweep at $1 \mathrm{~Hz}$; $\mathbf{c}$ dependence of moduli of ss-PUs and cc-PUs on shear strain amplitude sweep (shear strain $\gamma$ ranging from $0.1 \%$ to $120 \%$ ) at a fixed frequency of $1 \mathrm{~Hz}$; d viscoelastic properties of ss-PUs upon a periodic change of oscillation shear force to achieve

frequency sweep mode (Fig. 6a) and temperature sweep mode (Fig. 6b). When the temperature was as low as $25^{\circ} \mathrm{C}$, the values of $\mathrm{G}^{\prime}$ were much higher than those of $\mathrm{G}^{\prime \prime}$ in the linear viscoelastic region, indicating their elastic properties. Furthermore, when increasing temperature from $25^{\circ} \mathrm{C}$ to 80 ${ }^{\circ} \mathrm{C}$, both the values of $\mathrm{G}^{\prime}$ and $\mathrm{G}^{\prime \prime}$ decreased, implying that the mobilities of ss-PUs polymer chains were temperature dependent. When the sweep temperature was over $120^{\circ} \mathrm{C}$, the obvious crossover-point of $\mathrm{G}^{\prime}$ and $\mathrm{G}^{\prime \prime}$ appeared, above which temperature the ss-PUs showed good mobility.

Moreover, self-healing of viscoelastic properties were studied and measured to further investigate and understand the self-healing ability of ss-PUs. Prior to this measurement, the dependence of moduli on the shear strain at a constant frequency of $1 \mathrm{~Hz}$ was studied and the results were indicated in Fig. 6c. As indicated, both the $\mathrm{G}^{\prime}$ and $\mathrm{G}^{\prime \prime}$ of ss-PUs and cc-PUs remained constants within the shear strain of $\sim 10 \%$. With the increase of the applied shear strain, both $\mathrm{G}^{\prime}$ and $\mathrm{G}^{\prime \prime}$ showed a significant drop, indicating a quasi-liquid state. As shown in Fig. 6d, both the $\mathrm{G}^{\prime}$ and $\mathrm{G}^{\prime \prime}$ modulus of ss-PUs increased gradually when applying a $5 \%$ shear strain for $1500 \mathrm{~s}$ at $25^{\circ} \mathrm{C}$. Upon changing the oscillation shear force to achieve a a $5 \%$ shear strain for $1500 \mathrm{~s}$ to a $100 \%$ shear strain for $500 \mathrm{~s}$; e viscoelastic properties of the reference cc-PUs upon a periodic change of oscillation shear force to achieve a $5 \%$ shear strain for $1500 \mathrm{~s}$ to a $100 \%$ shear strain for $500 \mathrm{~s}$; $\mathbf{f}$ stress relaxation curves of ss-PUs at $25^{\circ} \mathrm{C}$ and $60{ }^{\circ} \mathrm{C}$

$100 \%$ shear strain for $500 \mathrm{~s}$ at $25{ }^{\circ} \mathrm{C}$, the $\mathrm{G}^{\prime}$ modulus suddenly dropped, resulting in the value of $\mathrm{G}^{\prime}$ modulus lower than that of $\mathrm{G}^{\prime \prime}$ modulus at this time. Then, when the oscillation shear force was changed to achieve a $5 \%$ shear strain again, both $\mathrm{G}^{\prime}$ and $\mathrm{G}^{\prime \prime}$ modulus was restored and the value of $\mathrm{G}^{\prime}$ was higher than that of $\mathrm{G}^{\prime \prime}$ again. Such a reversible recovery of the $G^{\prime}$ and $G^{\prime \prime}$ modulus could repeat for several times, indicating the self-healing of viscoelastic properties of ss-PUs. In contrast, the cc-PUs showed no self-healing behaviors of both $\mathrm{G}^{\prime}$ and $\mathrm{G}^{\prime \prime}$ modulus as that of the ss-PUs when changing the shear strain periodically (Fig. 6e).

In addition, the stress relaxation time of ss-PUs at $25{ }^{\circ} \mathrm{C}$ was relatively longer than that at $60^{\circ} \mathrm{C}$ (Fig. 6f), mainly due to two factors: firstly, the metathesis reaction of aromatic disulfide was faster at $60^{\circ} \mathrm{C}$ than that at $25{ }^{\circ} \mathrm{C}$; secondly, the hard microphase could partially immobilize the dynamic aromatic disulfide bonds because the disulfide bonds were trapped and immobilized in the viscoelastic hard segments. This feature endowed the ss-PUs with stability in dimension and excellent mechanical properties, and was beneficial for self-healing of the ss-PUs. 
Fig. 7 DSC $\mathbf{a}$ and TGA $\mathbf{b}$ traces of ss-PUs, compared with cc-PUs. Recycling of ss-PUs before $\mathbf{c}$ and after $\mathbf{d}$ compression molding at $80{ }^{\circ} \mathrm{C}$
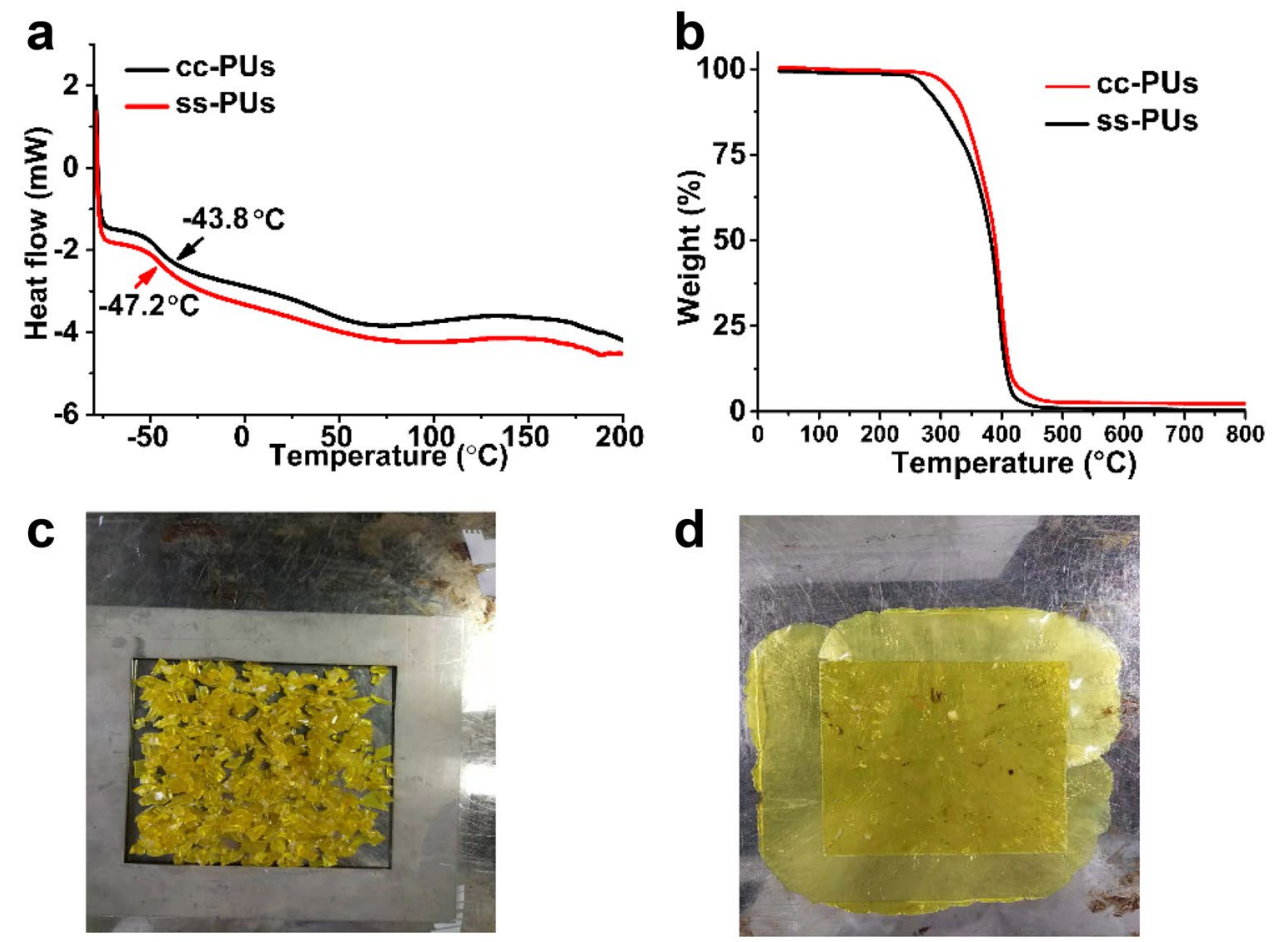

\section{Thermal properties of poly(urethane-urea) elastomers}

DSC thermograms were recorded to further characterize thermal properties of the elastomers. The transition of ss-PUs at $-47.2{ }^{\circ} \mathrm{C}$ was assigned to the glass transition arising from the PPG segment (Fig. 7a). While the $T_{\mathrm{g}}$ of cc-PUs was slightly increased to $-43.8{ }^{\circ} \mathrm{C}$. The thermal stabilities of ss-PUs and cc-PUs were assessed by TGA (Fig. 7b). The temperature ramps obtained under $\mathrm{N}_{2}$ flow showed that the samples were stable up to $250{ }^{\circ} \mathrm{C}$ for ss-PUs and $280^{\circ} \mathrm{C}$ for cc-PUs. The ss-PUs and cc-PUs were both thermoplastic and the ss-PUs could be reshaped and recycled after hot pressing under $10 \mathrm{MPa}$ at $80{ }^{\circ} \mathrm{C}$ for $20 \mathrm{~min}$ (Fig. $7 \mathrm{c}$ and d). These recycled ss-PUs should also be self-healable through the metathesis of the aromatic disulfide, just like their original samples. The mechanical properties and selfhealing efficiencies of the ss-PUs after 3 repeated recycling cycles were determined to be just as high as those of the original samples (Table 3).
Table 3 The mechanical properties and self-healing efficiency of ss-PUs at $25^{\circ} \mathrm{C}$ after recycling. Means, and standard deviations from five specimens

\begin{tabular}{lllll}
\hline $\begin{array}{l}\text { Recycling } \\
\text { times }\end{array}$ & $\begin{array}{l}\text { Ultimate tensile } \\
\text { strength } \\
\text { (MPa) }\end{array}$ & $\begin{array}{l}\text { Elongation } \\
\text { at break }(\%)\end{array}$ & $\begin{array}{l}R_{\sigma} \\
(\%)\end{array}$ & $\begin{array}{l}R_{\varepsilon} \\
(\%)\end{array}$ \\
\hline 1\# & $4.47 \pm 0.11$ & $851 \pm 33.1$ & & \\
1\# self-healing for 24 h & $4.15 \pm 0.10$ & $828 \pm 9.7$ & $92.8 \pm 2.2$ & $97.3 \pm 1.1$ \\
2\# & $4.31 \pm 0.16$ & $858 \pm 14.5$ & & \\
2\# self-healing for 24 h & $4.15 \pm 0.19$ & $826 \pm 8.7$ & $96.3 \pm 4.4$ & $96.3 \pm 1.0$ \\
3\# & $4.12 \pm 0.16$ & $830 \pm 11.8$ & & \\
3\# self-healing for 24 h & $4.08 \pm 0.12$ & $777 \pm 44.1$ & $99.0 \pm 2.9$ & $93.6 \pm 5.3$ \\
\hline
\end{tabular}




\section{Conclusion}

In conclusion, we successfully designed and prepared a novel, transparent, robust, and aromatic disulfide containing poly(urethane-urea) ss-PUs which was characterized and verified by ${ }^{1} \mathrm{H}-\mathrm{NMR}$, FT-IR and GPC. The microphase separation structure of ss-PUs was verified by AFM. It was noteworthy that ss-PUs possessed well heat-resistance $\left(T_{\mathrm{d}}=250^{\circ} \mathrm{C}\right)$, robust mechanical strengths $(4.20 \pm 0.10 \mathrm{MPa})$, excellent elongation at break $(954 \pm 35.6 \%)$ and Young's modulus $(16.6 \pm 0.6 \mathrm{MPa})$. By virtue of the metathesis of aromatic disulfide and the steric hindrance of the alicyclic IPDI, the ss-PUs achieved excellent self-healing abilities at room temperature compared with the reference cc-PUs. The dynamic processes of self-healing were monitored on both a micro-scale and macro-scale, for example, a full-cut sample could weight itself after self-healing for $10 \mathrm{~min}$ at $25^{\circ} \mathrm{C}$ and a scratch healed completely after self-healing for $8 \mathrm{~h}$ at $25{ }^{\circ} \mathrm{C}$. Moreover, the self-healing of the mechanical properties was investigated quantitively by tensile tests, and the results revealed a full recovery of these mechanical properties with a self-healing efficiency of $\sim 90 \%$ after self-healing for $12 \mathrm{~h}$ at $25{ }^{\circ} \mathrm{C}$, indicating the ability of the polymer chains to reconstruct at the cut interface. The viscoelastic properties of ss-PUs were measured by rheological experiments. Interestingly, the ss-PUs showed a reversible recovery of both the $G^{\prime}$ and $G^{\prime \prime}$ moduli which could repeat for several times, indicating the self-healing of viscoelastic of ss-PUs. Finally, the ss-PUs could be reshaped and recycled after hot pressing under $10 \mathrm{MPa}$ at $80^{\circ} \mathrm{C}$. These recycled ss-PUs still possessed excellent self-healing abilities after 3 recycling cycles. The self-healing poly(urethane-urea) system obtained in this work would be applied to protective coatings, soft robotics, wearable electronics, and so on.

Acknowledgements This work was supported by Keshun Waterproof Technology Co., Ltd.

Authors contribution Jin He: Methodology, Validation, Formal analysis, Investigation, Data curation, Writing-original draft. Fangfang Song: Methodology, Validation, Review \& editing. Xiong Li: Investigation, Review \& editing. Liyi Chen: Investigation, Review \& editing. Xingyu Gong: Conceptualization, Resources, Supervision, Project administration. Weiping Tu: Conceptualization, Supervision.

Open Access This article is licensed under a Creative Commons Attribution 4.0 International License, which permits use, sharing, adaptation, distribution and reproduction in any medium or format, as long as you give appropriate credit to the original author(s) and the source, provide a link to the Creative Commons licence, and indicate if changes were made. The images or other third party material in this article are included in the article's Creative Commons licence, unless indicated otherwise in a credit line to the material. If material is not included in the article's Creative Commons licence and your intended use is not permitted by statutory regulation or exceeds the permitted use, you will need to obtain permission directly from the copyright holder. To view a copy of this licence, visit http://creativecommons.org/licenses/by/4.0/.

\section{References}

1. Imato K, Takahara A, Otsuka H (2015) Self-Healing of a CrossLinked Polymer with Dynamic Covalent Linkages at Mild Temperature and Evaluation at Macroscopic and Molecular Levels. Macromolecules 48(16):5632-5639

2. Kim C, Yoshie N (2018) Polymers healed autonomously and with the assistance of ubiquitous stimuli: how can we combine mechanical strength and a healing ability in polymers? Polym J 50(10):919-929

3. White SR, Moore JS, Sottos NR, Krull BP, Santa Cruz WA, Gergely RC (2014) Restoration of large damage volumes in polymers. Science 344(6184):620-623

4. White SR, Blaiszik BJ, Kramer SLB, Olugebefola SC, Moore JS, Sottos NR (2011) Self-healing Polymers and Composites. Am Sci 99(5):392-399

5. Zhang ZP, Rong MZ, Zhang MQ (2018) Research Progress of Processing of Crosslinked Polymers Based on Reversible Covalent Chemistry: a New Challenge to the Development of Polymer Engineering. Acta Polym Sin 7:829-852

6. Ahn BK, Lee DW, Israelachvili JN, Waite JH (2014) Surfaceinitiated self-healing of polymers in aqueous media. Nat Mater 13(9):867-872

7. Yanagisawa Y, Nan YL, Okuro K, Aida T (2018) Mechanically robust, readily repairable polymers via tailored noncovalent crosslinking. Science 359(6371):72-76

8. Bastings MMC, Koudstaal S, Kieltyka RE, Nakano Y, Pape ACH, Feyen DAM, Slochteren FJV, Doevendans PA, Sluijter JPG, Meijer EW (2014) A Fast pH-Switchable and Self-Healing Supramolecular Hydrogel Carrier for Guided, Local Catheter Injection in the Infarcted Myocardium. Adv Healthc Mater 3(1):70-78

9. Rostamiyan Y, Rezaei M (2018) The effect of nano zirconium dioxide and drilling on the buckling strength of epoxy based nanocomposites. Mater Chem Phys 212:523-532

10. Rostamiyan Y, Fereidoon A, Rezaeiashtiyani M, Mashhadzadeh AH, Salmankhani A (2015) Experimental and optimizing flexural strength of epoxy-based nanocomposite: effect of using nano silica and nano clay by using response surface design methodology. Mater Design 69:96-104

11. Rostamiyan Y, Youseftabar H, Azadi R (2018) Experimental study on the effect of nano zirconia on mechanical strength and microstructure of damaged epoxy-nanocomposites. Mater Res Express 6(2):5046

12. Binder WH (2015) Self-healing polymers. Polymer 69:215

13. White SR, Sottos NR, Geubelle PH, Moore JS, Kessler MR, Sriram SR, Brown EN, Viswanathan S (2001) Autonomic healing of polymer composites. Nature 409(6822):794-797

14. Huang MX, Yang JL (2011) Facile microencapsulation of HDI for self-healing anticorrosion coatings. J Mater Chem 21(30):11123-11130

15. Kim DM, Song IH, Choi JY, Jin SW, Nam KN, Chung CM (2018) Self-Healing Coatings Based on Linseed-Oil-Loaded Microcapsules for Protection of Cementitious Materials. Coatings 8(11):404

16. Chu K, Song BG, Yang HI, Kim DM, Lee CS, Park M, Chung CM (2018) Smart Passivation Materials with a Liquid Metal Microcapsule as Self-Healing Conductors for Sustainable and Flexible Perovskite Solar Cells. Adv Funct Mater 28 (22):1800110.1-1800110.9

17. Toohey KS, Sottos NR, Lewis JA, Moore JS, White SR (2007) Self-healing materials with microvascular networks. Nat Mater 6(8):581-585 
18. Nan F, Yan Z (2019) Light-Driven Self-Healing of Nanoparticle-Based Metamolecules. Angew Chem Int Ed Engl 58(15):4917-4922

19. Du WN, Jin Y, Shi LJ, Shen YC, Lai SQ, Zhou YT (2020) NIRlight-induced thermoset shape memory polyurethane composites with self-healing and recyclable functionalities. Compos Part B-Eng 195:108092

20. Wang H, Yang Y, Zhang M, Wang Q, Xia K, Yin Z, Wei Y, Ji Y, Zhang Y (2020) Electricity-Triggered Self-Healing of Conductive and Thermostable Vitrimer Enabled by Paving Aligned Carbon Nanotubes. ACS Appl Mater Inter 12(12):14315-14322

21. Pu W, Fu D, Wang Z, Gan X, Lu X, Yang L, Xia H (2018) Realizing Crack Diagnosing and Self-Healing by Electricity with a Dynamic Crosslinked Flexible Polyurethane Composite. Adv Sci (Weinh) 5(5): 1800101

22. Ahmed AS, Ramanujan RV (2015) Magnetic Field Triggered Multicycle Damage Sensing and Self Healing. Sci Rep-Uk 5:13773

23. Ghosh A, Dimitrov DI, Rostiashvili VG, Milchev A, Vilgis TA (2010) Thermal breakage and self-healing of a polymer chain under tensile stress. J Chem Phys 132(20):204902

24. Nevejans S, Ballard N, Miranda JI, Reck B, Asua JM (2016) The underlying mechanisms for self-healing of poly(disulfide)s. Phys Chem Chem Phys 18(39):27577-27583

25. Azcune I, Odriozola I (2016) Aromatic disulfide crosslinks in polymer systems: Self-healing, reprocessability, recyclability and more. Eur Polym J 84:147-160

26. Zhang MY, Zhao FQ, Luo YJ (2019) Self-Healing Mechanism of Microcracks on Waterborne Polyurethane with Tunable Disulfide Bond Contents. ACS Omega 4(1):1703-1714
27. Zhao DL, Liu SS, Wu YF, Guan T, Sun N, Ren BY (2019) Selfhealing UV light-curable resins containing disulfide group: Synthesis and application in UV coatings. Prog Org Coat 133:289-298

28. Li XP, Yu R, He YY, Zhang Y, Yang X, Zhao XJ, Huang W (2019) Self-Healing Polyurethane Elastomers Based on a Disulfide Bond by Digital Light Processing 3D Printing. ACS Macro Lett 8(11):1511-1516

29. Rekondo A, Martin R, de Luzuriaga AR, Cabanero G, Grande HJ, Odriozola I (2014) Catalyst-free room-temperature self-healing elastomers based on aromatic disulfide metathesis. Mater Horiz 1(2):237-240

30. Kim SM, Jeon H, Shin SH, Park SA, Jegal J, Hwang SY, Oh DX, Park J (2018) Superior Toughness and Fast Self-Healing at Room Temperature Engineered by Transparent Elastomers. Adv Mater 30 (1):1705145.1-1705145.8

31. Wu DY, Meure S, Solomon D (2008) Self-healing polymeric materials: a review of recent developments. Prog Polym Sci 33(5):479-522

32. Zhou JH, Yang YL, Qin R, Xu M, Sheng YM, Lu X (2020) Robust Poly(urethane-amide) Protective Film with Fast Self-Healing at Room Temperature ACS Appl Polym Mater 2 (2):285-294

Publisher's Note Nature remains neutral with regard to jurisdictional claims in published maps and institutional affiliations. 